\title{
Reliability assurance of the thermal energy sources using the neural network modelling
}

\author{
Irina Akhmetova ${ }^{1}$, Elena Balzamova ${ }^{1}$, Veronika Bronskaya ${ }^{2, *}$, Denis Balzamov ${ }^{1}$ and Olga Kharitonova $^{2}$ \\ ${ }^{1}$ Kazan State Power Engineering University, 420066, 51 Krasnoselskaya Street, Kazan, Russian Federation \\ ${ }^{2}$ Kazan National Research Technological University, 420015, 68 Karl Marx Street, Kazan, Russian Federation
}

\begin{abstract}
A software package for neural network modelling, analysis and decision-making to improve the reliability of the heat supply system is presented. The features of heat sources and heating networks are taken into account when modelling. The trends and recommendations for improving reliability are presented.
\end{abstract}

\section{Introduction}

One of the main principles of the modern paradigm of energy systems is to strengthen the role of the consumer in the energy supply. This principle is implemented within the concept of the active consumer (AC), whose functions are to regulate and optimize the schedule of personal consumption from their own sources and energy storage in order to increase the efficiency and reliability of both the consumer and the entire energy system.

Different aspects of the operation and management of AC modes are considered as part of the energy supply of the system in the number of research [1-6]. At the same time, these technologies are essential for the heat supply systems (HSS), which are the largest consumers of fuel and energy.

During the operation of modern HSS, especially in conditions of increasing heat loads, there are a number of problems associated with meeting the requirements focused on the volume and reliability of providing consumers by the heat energy. Creating alternating current in the system

(the active heat energy consumer) with its own

sources of heat energy (SH) provide an additional reserve of power and time, which reduces the load on the centralized energy system and thereby improves the quality and reliability of heat supply.

Thus, one of the key tasks of the AC in the HSS is to improve the reliability of operations. The methodological problems that need to be solved to achieve this goal are the analysis of the reliability of energy systems as a whole and in the HSS. At the same time, the inclusion of AC in the HSS creates the new aspects of these tasks and requires the use of new methodological approaches to solve them.

When developing the methods of analysis and optimization of the reliability of HSS with the participation of AC, two main areas of research can be distinguished. The first area is related to the analysis and optimization of the reliability of heat supply to consumers taking into account the AC function in the system, provided that the number of nodes and capacity change.

The second one is the task of determining the quantity, location, AC power, as well as other ways to ensure the reliability of the system.

The first reliability problem is considered, which consists in determining such a structure (distribution though the systems) of the values of the reliability parameters of the HSS elements (failure intensity and recovery) that provide the necessary level of the reliability of the heat supply to consumers, including alternating current, taking into account their additional reserve with minimal costs for achieving these parameters in the range of their acceptable values.

To estimate the level of the reliability of consumers, it is important to determine the probability of reliable operation.

The task of reliability assurance is solved in stages:

1) determining the relationship between the integral parameters of the reliability of the HSS elements;

2) modeling the post-accident modes of the HSS;

3 ) the formalization of the problem of determining the optimal parameters of the reliability of the HSS elements.

\section{Calculation of the reliability}

There is a solution for the first stage of analysis and optimization of the reliability of the heat supply to consumers, taking into account the $\mathrm{AC}$ function in the article. In connection with it, the perspective is to develop optimal control algorithms that, on the one hand, provide control and, on the other hand, implement an optimal heating strategy that minimizes energy consumption based on artificial neural networks.

When calculating the reliability of thermal energy sources, a framework AForge.NET [7] was selected and an artificial neural network is implemented. For training and testing neural networks, sets of training and testing

* Corresponding author: dweronika@mail.ru 
pairs of vectors were formed to determine input and output variables (table 1).

Table 1. Input and output parameters of the neural network.

\begin{tabular}{|c|c|}
\hline Input & Output \\
\hline Open air temperature & Energy consumption \\
\cline { 1 - 1 } The intensity of solar radiation & \\
\cline { 1 - 1 } $\begin{array}{c}\text { Temperature of the supplied } \\
\text { heat transfer agent }\end{array}$ & $\begin{array}{c}\text { Optimal temperatures of } \\
\text { the supplied heat } \\
\text { transfer agent } \\
\text { reom }\end{array}$ \\
\cline { 1 - 1 } $\begin{array}{c}\text { Temperature of the air in the } \\
\text { The schedule of use of the } \\
\text { room. }\end{array}$ \\
\hline
\end{tabular}

Training and testing data samples were made from experimental data. Neural network training is more efficient when input and output variables are normalized.

The network has five neurons in the input layer, ten ones in the hidden layer and two ones in the output layer (network 5-10-2) (figure 1).

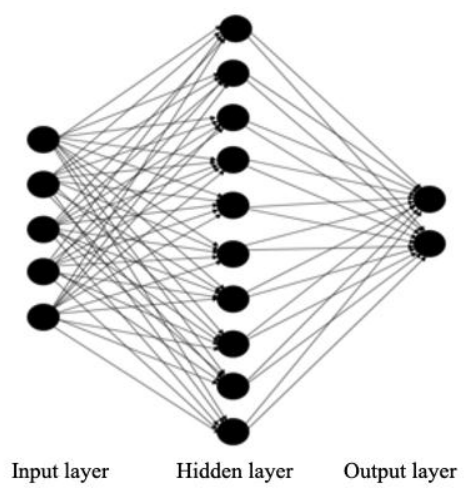

Fig.1. The neural network structure.

Training and testing vectors are formed from a set of input and output data.

The artificial neural network was implemented in C\# language in the Visual Studio development environment using the a Forge Neuro library [7]. In the course of this work, Windows Forms application that performs the functions of loading a training sample from a file, setting the necessary training accuracy and entering a vector to get the results of the neural network is created. The application interface is shown in figure 2 .

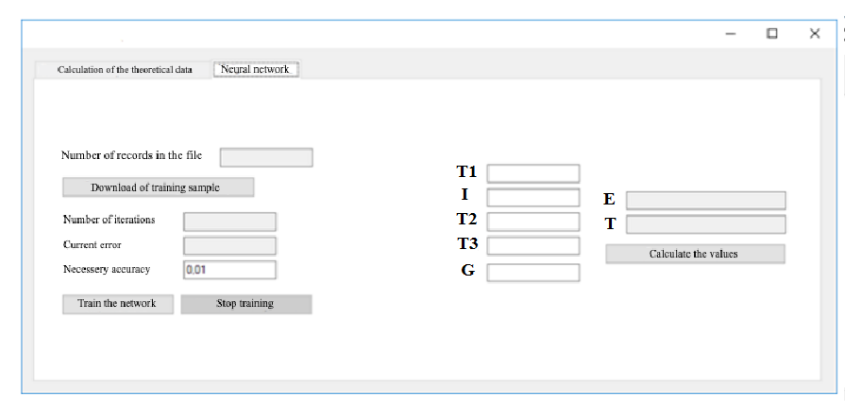

Fig. 2. The application interface for working with a neural network.

\section{Conclution}

Thus, the application based on a neural network fundamentally develops the scientific basis of the problem of the energy consumption management and the results of its application in practice will provide a significant effect of saving fuel and energy resources.

\section{References:}

1. D.S. Balzamov, I.G. Akhmetova, E.Y. Balzamova, G.I. Oykina, V.V. Bronsrkaya Options for organizing own sources of energy supply at the facilities of generating companies based on steam screw machines, Journal of Physics: Conference Series, 1399, 055018 (2019)

2. D.S. Balzamov, E.Y. Balzamova, S.R. Ibatullin, L.S. Sabitov Efficiency increase of gas turbine work in the summer period, IOP Conference Series: Materials Science and Engineering, 570, 012008 (2019)

3. D.S. Balzamov, L.S. Sabitov, B.F. Timershin, E.Yu. Balzamova Evaluation of the applicability of preevaporative cooling of air in front of the cooling tower in the conditions of the third climatic zone of the Russian Federation, IOP Conference Series: Materials Science and Engineering, 412, 012006 (2018)

4. D.S. Balzamov, L.S. Sabitov, B.F. Timershin, E.Yu. Balzamova Increase of efficiency of heat sources work due to application of condensation economizers on an example of a boiler PTVM-180, IOP Conference Series: Materials Science and Engineering, 412, 012007 (2018)

5. G.A. Aminova, G.V. Manuiko, T.V. Ignashina, V.V. Bronskaya, N.E. Kharitonova, G.S. D'Yakonov, V.P Arkhireev Optimal parameters of butadiene polymerization in the synthesis of rubber on a neodymium-containing catalytic system, Theoretical Foundations of Chemical Engineering, 40, pp. 59-67 (2006)

6. G.A. Aminova, M.D. Bronshtejn, G.V. Manujko, T.V. Ignashina, V.V. Davydova, O.V. Antonova, G.S. D'yakonov, I.G. Reshetova, N.E. Kharitonova Method of solution of a system of equations describing the continuous process of polymerization under conditions of a polyaddition reaction., Inzhenerno-Fizicheskii Zhurnal, 75, pp. 165-169 (2002)

7. O.S. Kharitonova, V.V. Bronskaya, T.V. Ignashina, A.A. Al-Muntaser, L.E. Khairullina Modeling of absorption process using neural networks, IOP Conference Series: Earth and Environmental Science, 315, 032025 (2019) 